\title{
Radyolojik bulgularla submandibular bezde dev siyalolit: Olgu sunumu*
}

\section{Giant sialolith in submandibular gland with radiological findings: A case report}

\author{
Sedef Ayşe Taşyapan ${ }^{1} \oplus$, Ahmet Faruk Ertürk ${ }^{1} \oplus$, Illknur Özcan ${ }^{1} \oplus$
}

* Bu olgu sunumu 2019 yilı 25. Uluslararası TDB Diş Hekimliği Kongresinde Poster Bildiri Olarak Sunulmuştur.

1 İstanbul Üniversitesi, Diș Hekimliği Fakültesi, Ağız, Diş ve Çene Radyolojisi Anabilim Dalı, İstanbul, Türkiye

ORCID: S.A.T. 0000-0002-1880-9276; A.F.E. 0000-0002-4404-1547;

İ.Ö. 0000-0001-9006-5630

Sorumlu yazar/Corresponding author: Ahmet Faruk Ertürk,

İstanbul Üniversitesi, Diş Hekimliği Fakültesi, Ağız, Diş ve Çene Radyolojisi Anabilim Dalı, İstanbul, Türkiye

E-posta: afebty@gmail.com

Başvuru/Submitted: 08.12.2019

Kabul/Accepted: 16.01 .2020

Atıf/Citation: Tasyapan SA, Erturk AF, Ozcan I. Giant sialolith in submandibular gland with radiological findings: a case report. Sağlık Bilimlerinde İleri Araștırmalar Dergisi 2020; 3(1): 20-25.

https://doi.org/10.26650/JARHS2020-656780
ÖZ

Siyalolit, bir tükürük bezi parankimi veya kanalı içerisinde, bir veya daha fazla sayıda, oval ya da yuvarlak formdaki kalsifik odak olarak tanımlanmaktadır. En sık submandibular tükürük bezinde ve 30-60 yaş aralığında görülmektedir. 46 yaşında erkek hasta dental tedavileri için İstanbul Üniversitesi Diş Hekimiği Fakültesi Ağız, Diş ve Çene Radyolojisi Kliniği’ne başvurmuştur. Panoramik radyografisinde rastlantısal olarak sağ mandibula angulus bölgesinde radyoopak bir oluşum görülmüştür. Klinik olarak ilgili bölgede herhangi bir semptom saptanamamıştır. Konik ışınlı bilgisayarlı tomografi incelemesinde sağ angulus bölgesinde, lingual alanda, iç yapısı mikst, hiperdens odak izlenmiş olup siyalolit olduğu tespit edilmiştir. Ultrasonografide ise submandibular tükürük bezi kanalı içerisinde olduğu belirlenmiştir. Herhangi bir semptom bulunmaması nedeniyle hastanın düazenli takibi sağlanmıştır. Klinik ve radyografik bulgular ile siyalolitin lokalizasyon ve ebatlarının belirlenmesi tedavi planlamasında önemlidir. Bu vaka sunumunda asemptomatik büyük boyutlu bir siyalolit olgusunun radyolojik bulgularını sunmak amaçlanmıştır.

Anahtar Kelimeler: Siyalolit, konik ışınlı bilgisayarlı tomografi, ultrasonografi

\section{ABSTRACT}

A sialolith is defined as one or more calcific foci in oval or round form within a parenchyma or duct of a salivary gland. It is most commonly seen in the submandibular salivary gland and in the 30-60 age range. A 46-year-old male patient was admitted to the Department of Oral and Maxillofacial Radiology of Istanbul University Faculty of Dentistry for dental treatment. A panoramic radiography incidentally showed a radiopaque formation in the right mandible angulus. No symptoms were detected in the clinically relevant region. A cone beam computed tomography showed a mixed, hyperdense focus in the lingual area in the right angulus region and a sialolith was detected. On ultrasonography, a sialolith was found in submandibular salivary gland duct. Due to the absence of any symptoms, regular followup was provided. The determination of localization and size of the sialolith with clinical and radiographic findings are important in treatment planning. In this case report, we aimed to present the radiological findings of an asymptomatic case of a large sialolith.

Keywords: Sialolith, cone-beam computed tomography, ultrasonography 


\section{GİRIŞ}

Siyalolit, az miktarda inorganik ve organik bileşenlerle birlikte apatit yapısını gösteren kalsiyum fosfat ve kalsiyum karbonat gibi kalsiyum tuzlarının yoğunlaşması ile oluşmaktadır. Tükürük bezi parankimi veya kanalı içerisinde yerleşim göstermektedir. Bir veya daha fazla sayıda oluşabilir. Genellikle oval ya da yuvarlak formdaki kalsifik odaklardır. ${ }^{1,2}$ Siyalolit, tükürük bezlerinin en sık görülen ikinci hastalığ olup her 1000 erişkin hastanın 12'sinde siyalolit olduğu tahmin edilmektedir $(3,4)$.

Siyalolit sıklıkla 30-60 yaş aralığında ve erkeklerde izlenmektedir. ${ }^{5} \% 80-95$ submandibular bezde, \%5-20 parotis bezinde ve \%1-2 dil altı ve minör tükürük bezlerinde görülmekte olup submandibular bezde sık görülme nedeni olarak yer çekimine karşı tükürük akışını gerektiren anatomik pozisyonu, daha uzun ve daha fazla kıvrımlı kanalı ve müsin bakımından zengin alkalin tükürük üretimi olduğu düşünülmektedir $(5,6)$. Siyalolitler sıklıkla intraduktal yerleşim göstermektedir (6).

Klinik bulguları genellikle yemek sırasında veya sonrasında tekrarlayan ağrı ve şişliktir. Boyutlarının büyümesi ile birlikte tıkanıklığa neden olmaktadır, buna bağlı olarak şişlik ve ağrıya ek olarak enfeksiyon da gelişebilmektedir (7). Boyutları büyük boyutlara ulaştığında palpe edilebilmekte olup küçük boyutlu siyalolitler radyografik muayenede rastlantısal olarak izlenmektedir.

Radyografik tanı koyulmasında panoramik radyografi, bilgisayarlı tomografi, konik ışınlı bilgisayarlı tomografi, sialografi, ultrasonografi ve manyetik rezonans görüntüleme gibi birçok teknik kullanılmaktadır (7). Bu olgu sunumunda, asemptomatik büyük boyutlu bir siyalolit olgusunun radyolojik bulgularını sunulacaktır.

\section{OLGU SUNUMU}

46 yaşında erkek hasta dental tedavileri için İstanbul Üniversitesi Diş Hekimliği Fakültesi Ağız, Diş ve Çene Radyolojisi Kliniğìne başvurmuştur. Hastadan gönüllü bilgilendirilmiş onam formu ve izin yazısı alınmıștır. Hastanın anamnezinde herhangi bir sistemik hastalığının olmadığı öğrenilmiştir. Yapılan intraoral muayenede hastada periodontal problemler, diş çürükleri ve 46 nolu diş bölgesinde rezidüel kök görülmüştür.

Panoramik radyografisinde intraoral muayeneye ek olarak kronik periodontitise bağlı ileri derecede kemik kayıpları izlenmiş olup sağ mandibula angulus bölgesinde radyoopak bir odak görülmüştür (Şekil 1).

İmplant planlaması için hastadan alınan konik 1şınlı bilgisayarlı tomografi görüntülerinde sağ mandibular kanalda ramus bölgesinde bifid kanal formasyonu ve sağ angulus bölgesinde, lingual alanda, yu-

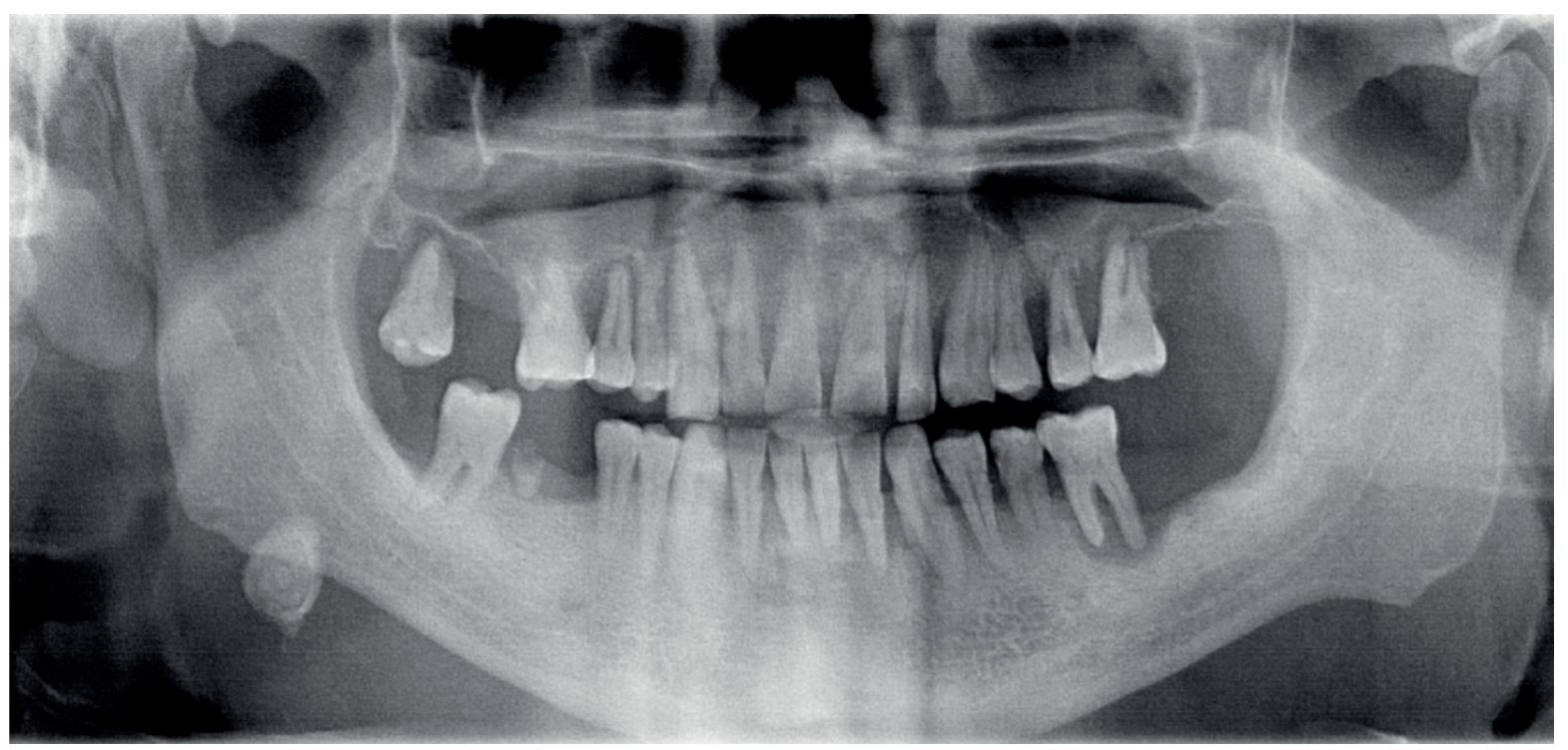

Şekil 1. Hastanın panoramik radyografisinde sağ angulus bölgesinde radyoopak odak izlenmektedir 
muşak doku içerisinde, submandibular tükürük bezi bölgesinde, iç yapısı mikst, 9.7x11.3x12.5 mm boyutlarında hiperdens odak izlenmiştir (Şekil 2a,2b,2c). $\mathrm{Bu}$ bulgular siyalolit yönünde yorumlanmış olup konik ışınlı bilgisayarlı tomografinin yumuşak doku incelemede ayrıntı göstermemesi nedeniyle ultrasonografi ile değerlendirilmesi uygun görülmüştür.

Ultrasonografi değerlendirmesinde siyalolitin

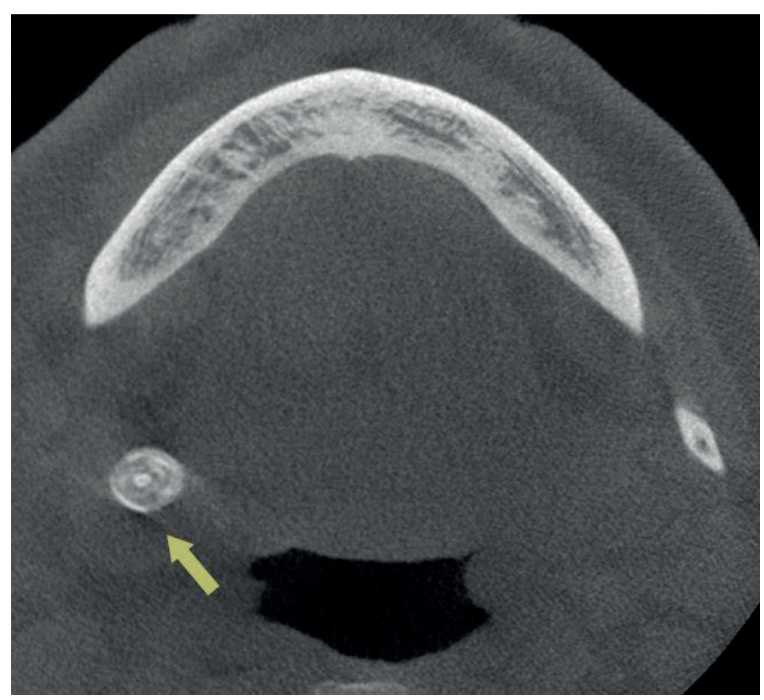

Şekil 2a. Hastanın aksiyal kesit konik ışınlı bilgisayarlı tomografi görüntüsünde submandibular tükürük bezi bölgesinde, iç yapısı mikst, düzgün sınırlı hiperdens odak görülmektedir submandibular tükürük bezinin kanalı içerisinde olduğu ve yaklaşık 9x11x12 mm boyutlarında olduğu tespit edilmiştir (Şekil 3a,3b). Bu boyutlar arasındaki ufak seviyedeki değişimler, ultrasonografinin dinamik bir görüntüleme yöntemi olması ve uygulayıcıya bağlı olarak değişkenlik gösterebilmesine bağlı olarak oluştuğu düşünülmektedir.

\section{TARTIŞMA}

Siyalolit, tükürük bezinin en sık görülen hastalıklarından biridir (8). Siyalolitlerin büyüklügü birkaç milimetreden birkaç santimetreye kadar değişebilmekte olup tipik olarak çapları 10 mm'den az olarak görülmektedir (8).

Siyalolitlerin gelişimini ve büyümesini; boşaltım kanalının çapı ve boylamı, tükürük akışının hızı, tükürügün alkalinitesi, tükürük sekresyonu içindeki müsin proteinleri ve miktarları, salgılanan tükürüğün Ca ve $P$ içeriği etkilemektedir (8). En sık submandibular tükürük bezlerinde izlenmekte olup dil altı veya küçük tükürük bezlerinde görülme sıklığı ise \% 1-2'dir (9). Bu olguda da submandibular bezde ve literatür ile uyumlu yaş ve cinsiyette izlenmektedir.

Submandibular tükürük bezindeki siyalolitlerin çoğu panoramik radyografilerde radyoopak oluşumlar olarak tespit edilir (6). Özellikle submandibular

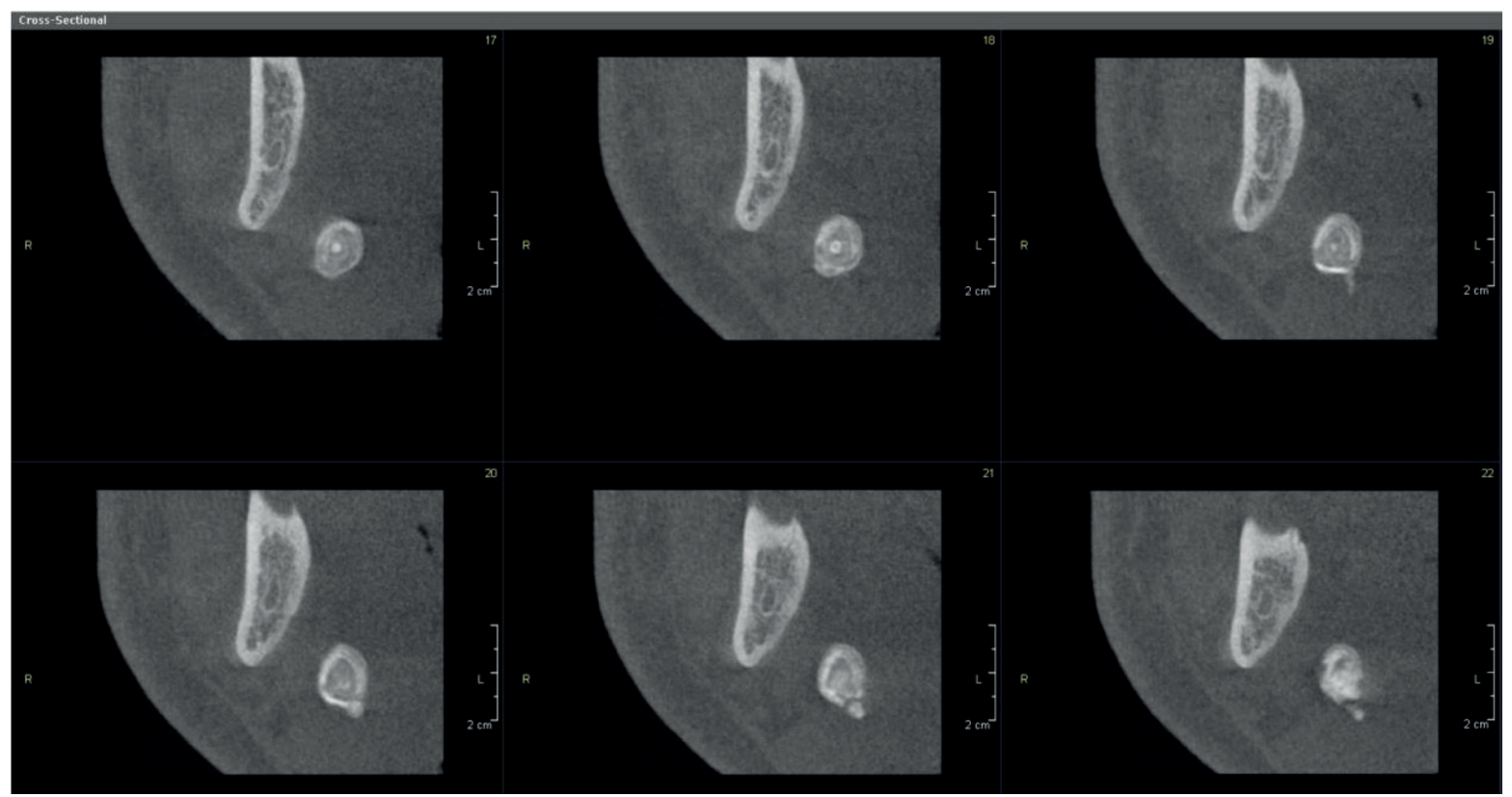

Şekil 2b. Hastanın cross-sectional kesitte konik ıșınlı bilgisayarlı tomografi görüntüsünde submandibular tükürük bezi bölgesinde, iç yapısı mikst, düzgün sınırlı hiperdens odak görülmektedir 


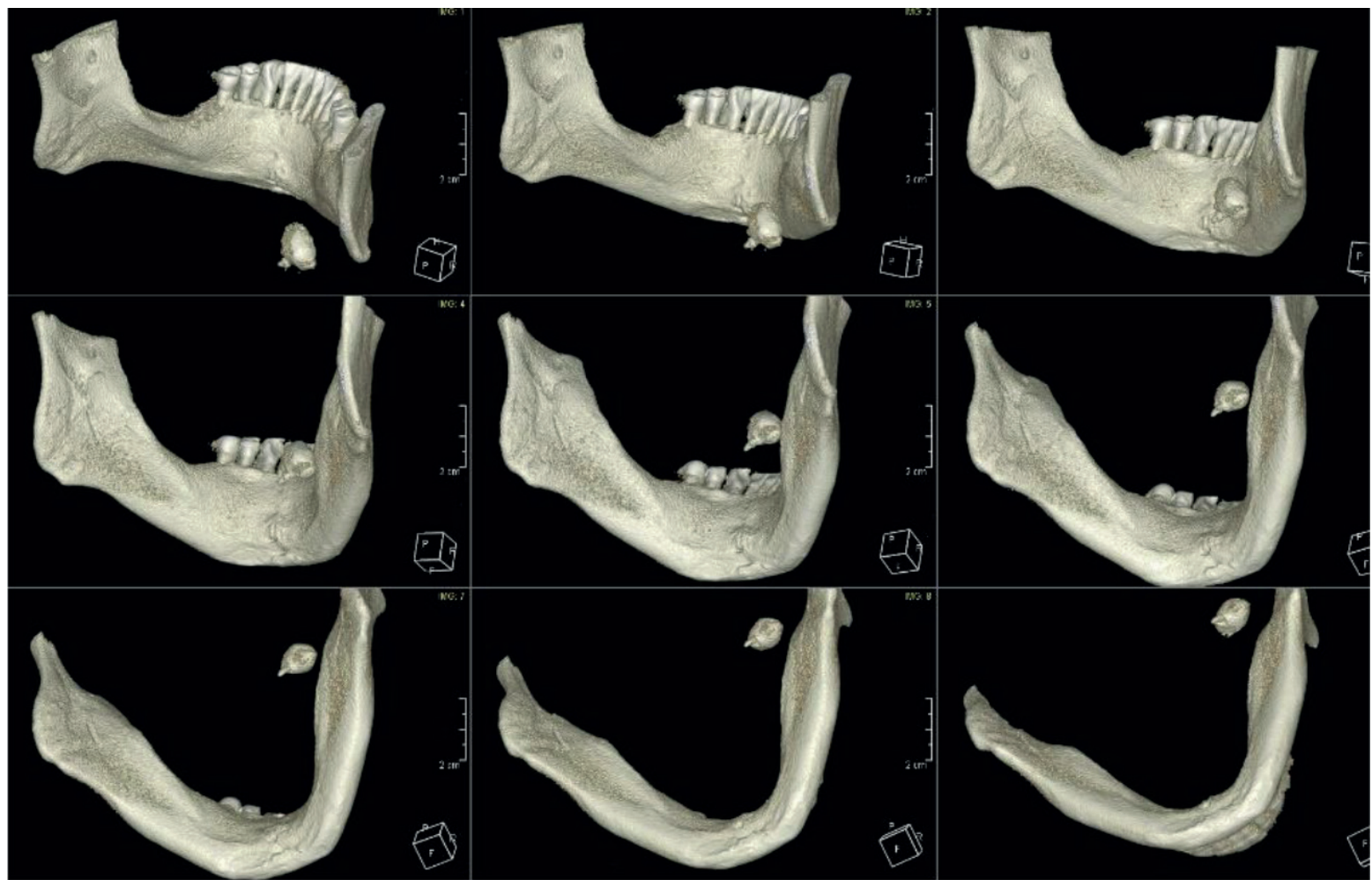

Şekil 2c. Hastanın 3D rekonstrüksiyon görüntüsünde çeşitli açılandırmalar ile siyalolit izlenebilmektedir

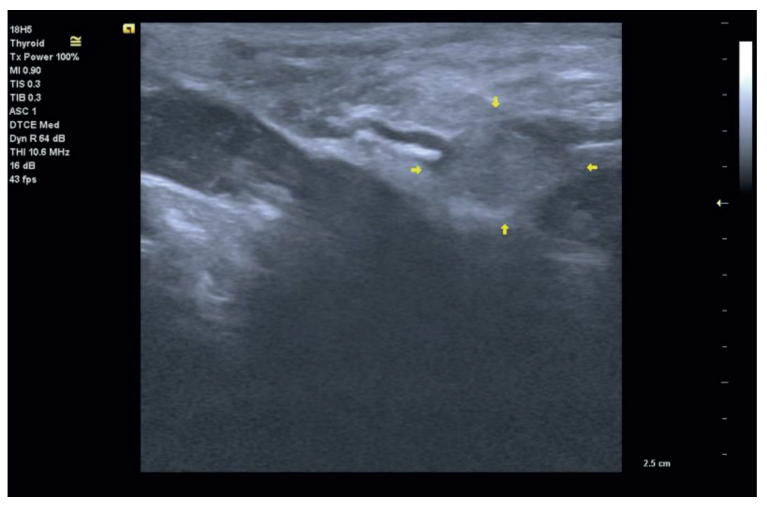

Şekil 3a. Hastanın ultrasonografi görüntüsünde submandibular bezin duktusunda yerleşim gösteren, oval formda hiperekoik alan izlenmektedir

tükürük bezinde yerleşim gösteren siyalolitler lokalizasyonları nedeniyle lenf nodu kalsifikasyonu, tonsilolit ve flebolit gibi durumlar ile karıştırılabilirler. Submandibular tükürük bezindeki siyalolitlerin tespitinde oklüzal radyografi de yarar sağlamaktadır. Fakat lokalizasyon ve ebatlarının tam belirlenebilmesi için günümüzde ileri görüntüleme yöntemleri tercih edilmektedir.

Konik ışınlı bilgisayarlı tomografi, daha düşük radyasyon dozu, kolay ulaşılabilirlik ve yüksek çözü-

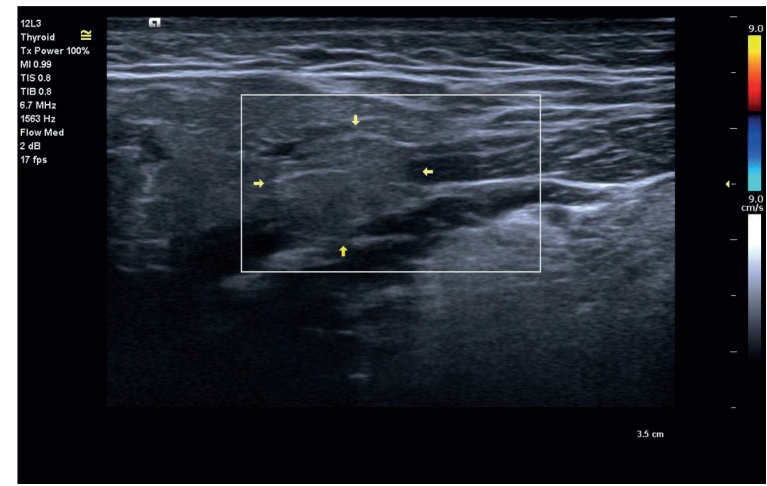

Şekil 3b. Hastanın renkli doppler ultrasonografi görüntüsünde ilgili bölgede herhangi bir vaskülarizasyon görülmemektedir

nürlük gibi özellikleri nedeniyle diş hekimliğinde kullanımı yaygınlaşmış olup siyalolitlerin tanısında, lokalizasyon ve boyut belirlenmesinde sıklıkla tercih edilmektedir. Fakat yumuşak doku görüntülemede yetersiz olması nedeniyle kontrast madde veya ek görüntüleme tekniği kullanımı gerektirmektedir. Bilgisayarlı tomografi ise küçük boyutlu ve semikalsifiye siyalolitlerin tespitinde bile başarılı olmasına rağmen yüksek radyasyon dozu ve yüksek maliyet nedeniyle tercih edilmemektedir (10). 
Ultrasonografi, noninvaziv bir teknik olması, daha ucuz maliyet, kolay ulaşılabilirlik ve iyonize radyasyon kullanılmaması gibi avantajları nedeniyle tercih edilmektedir. Buna ek olarak çok küçük boyutlu siyalolitlerde, uygun olmayan prob ve cihaz kullanımında, uygulayıcının yeterli bilgi ve deneyime sahip olmadığg durumlarda ultrasonografi ile görüntüleme uygun olmayabilir (11). Manyetik rezonans görüntüleme ise pahalı ve kolay bulunmaması nedeniyle rutinde kullanılmamaktadır. Sialografi ise invaziv bir teknik olması, kontrast madde alerjisi bulunabilmesi, akut enfeksiyon döneminde kullanılmaması gibi nedenlerden ötürü tercih edilmemektedir.

Klinik ve radyografik bulgular, doğru planlama ve tedavi için lokalizasyon ile büyüklüğün belirlenmesinde önemlidir (12). Kanal ağzının yakınında bulunan küçük bir siyalolit, bir lakrimal balon kateter veya lokal masaj yapılarak veya sırasıyla sakız veya sitrik asit gibi mekanik veya kimyasal siyalogoglar kullanılarak tükürük akışının uyarılması yoluyla kendiliğinden dişarı atılabilir $(13,14)$. Buna ek olarak ultrasonografi kullanımının yaygınlaşması ile birlikte ultrasonografi eşliğinde laparoskopik olarak siyalolitlerin çıkartılması tercih edilmektedir. Diğer taraftan çoklu veya büyük siyalolitler genellikle cerrahi yaklaşımları gerektirir (13).

$\mathrm{Bu}$ olguda, siyalolit büyük boyutlu olması ve tükürük bezi kanalı içerisinde yerleşim gösteriyor olmasına rağmen herhangi bir semptom vermemesi nadir bir durum olup tükürük bezi kanalının perforasyonu riski nedeniyle hasta sık takiplere çağrılmıştrr. Bu boyutlardaki siyalolitlerin laparoskopik olarak çıkartılması mümkün olmadığı için herhangi semptom varlığında hastaya cerrahi yaklaşım planlanmaktadır.

Hakem Değerlendirmesi: Dış bağımsız.

Peer Review: Externally peer-reviewed.

Yazar Katkıları: Çalışma Konsepti/TasarımS.A.T., A.F.E., İ.Ö.; Veri Toplama- S.A.T., A.F.E., İ.Ö.; Veri Analizi/Yorumlama- S.A.T., A.F.E., İ.Ö.; Yazı Taslağı- S.A.T., A.F.E., İ.Ö.; İçeriğin Eleştirel İncelemesi- S.A.T., A.F.E., İ.Ö.; Son Onay ve SorumlulukS.A.T., A.F.E., İ.Ö.; Malzeme ve Teknik Destek- S.A.T., A.F.E., İ.Ö.; Süpervizyon- İ.Ö.
Author Contributions: Conception/Design of Study- S.A.T., A.F.E., İ.Ö.; Data Acquisition- S.A.T., A.F.E., İ.Ö.; Data Analysis/Interpretation- S.A.T., A.F.E., İ.Ö.; Drafting Manuscript- S.A.T., A.F.E., İ.Ö.; Critical Revision of Manuscript- S.A.T., A.F.E., İ.Ö.; Final Approval and Accountability- S.A.T., A.F.E., İ.Ö.; Technical or Material Support- S.A.T., A.F.E., İ.Ö.; Supervision- İ.Ö.

Çıkar Çatışması: Yazarlar çıkar çatışması beyan etmemişlerdir

Conflict of Interest: Authors declared no conflict of interest.

Finansal Destek: Yazarlar finansal destek beyan etmemişlerdir.

Financial Disclosure: Authors declared no financial support.

\section{KAYNAKLAR}

1. Haas OL. Jr. et al. Sialolith removal in the submandibular region using surgical diode laser: report of two cases and literature review. Oral Maxillofac Surg, 2018;22(1): 105-111.

2. Takeda Y. et al. Sialolith of the submandibular gland with bone formation. Pathol Int, 2003;53(5): 309-312.

3. Biddle RJ., Arora S. Giant Sialolith of the Submandibular Salivary Gland. Radiol Case Rep, 2008;3(2): 101.

4. Rodrigues GHC. et al. Giant submandibular sialolith conservatively treated. Autops Case Rep, 2017;7(1): 9-11.

5. Arunkumar KV, Garg N, Kumar V. Oversized submandibular gland sialolith: a report of two cases. J Maxillofac Oral Surg, 2015;14(1): 116119.

6. Arslan S. et al. Giant sialolith of submandibular gland: report of a casedagger. J Surg Case Rep, 2015;2015(4).

7. Purcell YM. er al. The Diagnostic Accuracy of Contrast-Enhanced CT of the Neck for the Investigation of Sialolithiasis. AJNR Am J Neuroradiol, 2017;38: 2161-2166.

8. Iwai T. et al. Giant Sialolith of the Submandibular Gland. J Clin Diagn Res, 2017;11(8): ZJ03-ZJ04. 
9. Ledesma-Montes C. et al. Scanning electron micrographic features of a giant submandibular sialolith. Ultrastruct Pathol, 2007;31(6): 385391.

10. Van Der Meij EH, Karagozoglu KH, De Visscher JGAM. The value of cone beam computed tomography in the detection of salivary stones prior to sialendoscopy. International Journal Of Oral And Maxillofacial Surgery, 2018;47.2: 223227.

11. Thomas W. Walsh Douglas, Jennifer E. Rassekh, Christopher H. Accuracy of ultrasonography and computed tomography in the evaluation of patients undergoing sialendoscopy for sialolithiasis. Otolaryngology-Head and Neck Surgery, 2017;156.5: 834-839.
12. Jung JH. et al. A large sialolith on the parenchyma of the submandibular gland: A case report. Exp Ther Med, 2014;8(2): 525-526.

13. de Santana Santos T. et al. Intraoral approach for removal of large sialolith in submandibular gland. J Craniofac Surg, 2012;23(6):1845-1847.

14. Franco Aç, et al. Massive Submandibular Sialolith: Complete Radiographic Registration and Biochemical Analysis through X-Ray Diffraction. Case Rep Surg, 2014;2014: 659270. 